\title{
Bias and equivalence of the Strengths Use and Deficit COrrection Questionnaire in a South African context
}

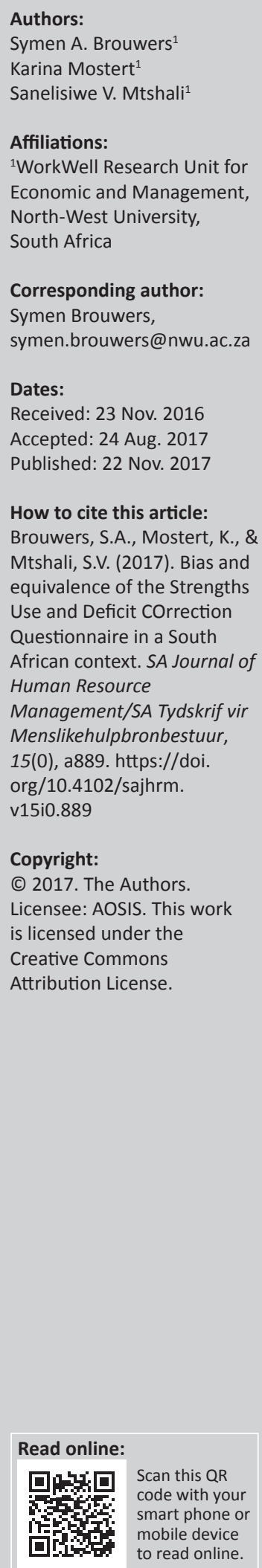

Orientation: Developing personnel into skilled employees is a major focus of managers and companies. Doing this in a valid way in a cross-culturally diverse working environment may be challenging. It is, therefore, important to investigate the cultural consistency of new tools that assist managers in reaching these personnel development goals.

Research purpose: Determine whether the Strengths Use and Deficit COrrection (SUDCO) questionnaire is universally applicable across the Nguni, Sesotho and West-Germanic language groups in South Africa by evaluating it statistically for bias and equivalence.

Motivation for the study: South African personnel management could gain valuable insights and outcomes when they aim to improve both strengths and weaknesses.

Research design, approach and method: The study employed semi-stratified sampling. A sample $(N=658)$ of employees in the banking sector participated in the study. The research focused on psychometric properties relating to bias, structural equivalence and reliability.

Main findings: A four-factor model fitted the data best. This model described perceived organisational support (POS) for strengths use, POS for deficit correction, strengths-use behaviour and deficit-correction behaviour. A multi-group confirmatory factor analysis for the direct comparison of the SUDCO's fit across the language groups (Nguni, Sesotho and WestGermanic) showed the 33 were unbiased against any of the three language groups and structured into the same four latent constructs.

Practical implications: In personnel development, employees and managers should understand the benefits of a combined strengths and deficit approach as relating to different language groups.

Contribution: The study contributes to literature a cross-culturally validated measure for the assessment of strengths and deficits.

\section{Introduction}

Talent management stands out among the human-capital challenges that organisations in South Africa face today. Among challenges such as leadership, retention and engagement, diversity and inclusion, workforce capability, and talent acquisition (Deloitte \& Touche, 2014), talent management makes up the largest component of business operating expenses. The average costs of talent management are estimated in the range of $70 \%-80 \%$ (Director, Cascio \& Boudreau, 2013). Therefore, to maintain a competitive advantage, organisations adopt a human-capital strategy with a similar level of precision and analyses as capital investments in plants and equipment (Echols, 2005). To optimise the effect of factors related to human capital on overall business performance, organisations strongly emphasise practices of performance management aimed at improving employee deficits (Aguinis, Gottfredson \& Joo, 2012). Positive dimensions underlying personnel development, such as strengths, have received relatively little attention, particularly from a cross-cultural perspective. The present study aims to close this gap between strengths and culture.

\section{Literature review}

\section{The Strengths Use and Deficit COrrection Questionnaire}

In an attempt to fill the gap of the one-sided focus on deficits, industrial psychologists proposed a shift towards positive psychology. One of the outcomes linked to this shift in thinking was the development of a strengths-based approach (hereafter: SBA) (Seligman, Park \& Steen, 2004). SBA is a positive aspect of psychology that focuses on peoples' strengths (Seligman \& Csikszentmihalyi, 2014). The value of an SBA is well documented in literature. This entails practices such as positive 
leadership, a strengths-based organisational culture and appropriate change management (e.g. appreciative inquiry). Evidence shows that these practices can help companies meet their business goals (Tombaugh, 2005). Furthermore, research indicates a positive association between the variable use of strengths with engagement (Van Woerkom, Oerlemans \& Bakker, 2016), performance (Tombaugh, 2005) and positive effect (Meyers \& Van Woerkom, 2016). Other findings show that SBA provides employees key support in achieving goals, which leads to an increased need for satisfaction and wellbeing (Linley, Nielsen, Gillett \& Biswas-Diener, 2010). The Strengths Use and Deficit COrrection (SUDCO) questionnaire is an extension of this line of thinking.

Van Woerkom et al. (2016) developed the SUDCO questionnaire with four dimensions in mind. The first two dimensions, perceived organisational support (hereafter POS) for strengths use and deficit correction, were based on the theory of perceived organisational support. Traditionally, POS has been conceptualised as the generalised beliefs about the extent to which an organisation supports its employees (Eisenberger, Fasolo, Davis-LaMastro, 1990; Eisenberger, Huntington, Hutchison \& Sowa, 1986). This construct is based on the social exchange theory, which postulates that employees reciprocate their salary and benefits by ensuring productivity and performance, provided they perceive their organisation would support them in turn (ArmstrongStassen \& Ursel, 2009). As a result, employees' form positive or negative perceptions based on the following actions: how an organisation creates meaningful jobs, handle employees who err and invest in establishing a positive working environment (Eisenberger, Huntington, Hutchison \& Sowa, 1986). Furthermore, employees view their organisation as supportive if individuals are allowed to participate in decision-making, deem the rewards system to be fair and are provided training (Allen, Shore \& Griffeth, 2003) which lead to opportunities for self-development and growth (Armstrong-Stassen \& Ursel, 2009).

A strength is a natural capacity for behaving, thinking or feeling in a way that allows optimal functioning and performance to fulfil one's goals (Linley \& Harrington, 2006). POS for strengths use, therefore, can be defined as the extent to which employees perceive organisations to support them by utilising their strengths and talents in the workplace. This dimension also shows a strong connection with the theory of strength-based psychological climate, which similarly is described as employees' perceptions of formal and informal practices, processes and procedures regarding their organisational support in the identification and use of strengths (Van Woerkom \& Meyers, 2014). Evidence suggests that POS for strengths use is a significant predictor of workrelated aspects such as burnout (Keenan \& Mostert, 2012), engagement (Keenan \& Mostert, 2012; Stander \& Mostert, 2013; Van Woerkom et al., 2016) and job performance (Van Woerkom \& Meyers, 2015).

POS for deficit correction can be defined as the extent to which employees perceive their organisations to support them in developing or correcting their deficits at work. Organisations apply processes for performance management to identify deficits and adopt interventions at various levels in the organisation. Such organisational input entails on-job learning, training and coaching to improve performance (Gilley, Gilley \& Kouider, 2010; Kirkpatrick, 2006). In a study by Ellinger (2003) involving four organisations, it was found that organisations' interventions to correct deficits resulted in improved learning, performance and innovation among employees. The same study also indicated benefits for the organisation such as saving costs, improving systems and sharing knowledge. Similarly, further studies conducted with leaders and employees suggest that working on deficits does improve performance (Longenecker, 2010; Zenger, 2008).

Even though organisations play a significant role in supporting their employees in strengths use and deficit correction, the individuals also need to be proactive in managing this development themselves. Based on this reasoning, proactive behaviour for strengths use can be defined as the employees' self-starting behaviour aimed at using their strengths in the workplace. Crant (2000) argues that proactive behaviour in the workplace means taking the initiative to improve current circumstances or create new ones by challenging the status quo, rather than passively adapting to present conditions. People who know their strengths, apply it by taking the initiative to improve their environment and build networks (Thompson, 2005). This process leads to higher levels of work engagement (Van Woerkom et al., 2016; Xanthopoulou, Bakker, Demerouti \& Schaufeli, 2009), increased performance (Corporate Leadership Council, 2002; Crant, 2000; Thompson, 2005) and an improved state of well-being (Govindji \& Linley, 2007).

Proactive behaviour in correcting deficits can be defined as employees' self-starting behaviour to help improve deficiencies in the workplace that may be perceived as hampering performance (Van Woerkom et al., 2016). In performance management, employees' performance is assessed and they receive feedback from their direct reporting line. During this process, employees' areas of development or deficits are identified. Employees who are proactive demonstrate the following behaviour patterns: familiarise themselves with the expected performance standards, request help from other team members (Torrente, Salanova, Llorens \& Schaufeli, 2012), spend more time practicing or doing on-the-job training (Ericsson, Nandagopal, \& Roring, 2009) and ask for feedback on their performance (Belschak \& Den Hartog, 2010). Findings show that employees' proactive behaviour towards deficit correction also leads to continuous learning (Rowold \& Schilling, 2006).

\section{Assessment within the South African context}

Psychometric assessments are used mainly in recruitment, selection and placement to secure employment or promotional opportunities. In South Africa, the use of tests for these purposes are highly regulated. In the labour market 
(including the banking sector) as promulgated in the Employment Equity Act 55 of 1998 (section 8), the use of psychometric assessments is prohibited unless it (1) had been scientifically shown to be valid and reliable, (2) can be applied fairly to all, (3) is not biased against any employee or group and (4) is classified by the Health Professions Council of South Africa (Department of Labour, 1998). The existence of laws prohibiting discrimination in the workplace does not always guarantee that women, people from different ethnic backgrounds, or those from other segments of the workforce have equal employment opportunities (Deloitte \& Touche, 2014). In several cases, information about the quality of assessment is emitted. Psychological development and assessment trends in South Africa are thus important for a comprehensive focus on the misuse of measures. Such misuse entails the following: measuring different groups, investigating test properties and applying test results without considering the differences in socio-cultural, economic and educational factors (Foxcroft \& Roodt, 2009).

\section{Bias and equivalence}

Examination of threats to fair assessment is categorised as bias and equivalence, and includes advanced statistical techniques to determine the impact of either. Analysis of bias and equivalence focuses on different levels or types of biases in which equivalence can be seen as the opposite pole of bias. In other words, when the test scores are equivalent, bias is absent (Van de Vijver \& Tanzer, 1997). Three sources of bias can be distinguished, namely, those of constructs, methods and items (Van de Vijver \& Leung, 1997).

Item bias refers to unwanted distractions of a scale at the item level (Van de Vijver \& Leung, 2011). The main concept linked to item bias is familiarity. Particular words or phrasing within the item may be unfamiliar to the person who is tested, thus leading to a loss of accessibility. People belonging to different cultural groups than the one in which the item was developed, thus may respond in a consistently dissimilar manner (He \& Van de Vijver, 2012; Meiring, Van de Vijver \& Rothmann, 2007). Furthermore, bias may be associated with events in the administration of the test, such as the interviewers' characteristics (e.g. gender, cultural group), communication problems (poor use of language by either party) or other procedural aspects when collecting the data (Van de Vijver \& Leung, 2011; Van de Vijver \& Tanzer, 1997).

At the opposite end of the scale is construct bias. This form of bias occurs when constructs differ in meaning or interpretation across cultures or language groups (He \& Van de Vijver, 2012). The logical underpinning would be that the construct under investigation is not part of universal human functioning, but an invention from within a particular cultural context. Between the extremes of item and construct bias, lies method bias. This form of bias can emerge because of the research method or weakness in the applied procedure during empirical studies (He \& Van de Vijver, 2012). On the other side, bias may occur because of cognitive strategies applied by the study participants in more complex performance tasks. As a result, method bias covers the terrain of construct and item bias. However, there are no set techniques to examine method bias (Podsakoff, MacKenzie \& Podsakoff, 2012).

The study of equivalence is an approach or method to assess bias. Equivalence is a measure of similar scores and an indication of the differences found within the scores. Score differences do not only consist of mean differences but also of measurement weights, measurement intercepts, structural means and measurement residuals. Weights and intercepts do model item bias. Uniform bias is found in the intercepts: one culture may score consistently higher or lower than another one, irrespective of the true level of the construct. Non-uniform bias is found in significant regression weights of an item on its applicable latent variable; the effect of culture is different in size for exponents who score high and low (Van de Vijver \& Leung, 1997). Structural means and measurement residuals serve to model properties of the construct; their assessment asks whether in each culture the starting point of the scale is similar; thus whether in each culture the scales can be juxtaposed, and will completely mirror each other without any deviations (Van de Vijver \& Leung, 2011).

\section{Applying mean score differences}

When a construct shows comparability across cultures, there is still sufficient room for individual variation within cultures, particularly for variables of development over people's lifespan. Relations of age and the SUDCO dimensions may be expected to have the same direction in different cultures, but they differ in strength. It is a challenge for most organisations to manage the often conflicting views and needs of a diverse workforce, covering a wide range of generations from the so-called Baby Boomers to Generation $X$ and Generation Y. Organisations who invest in career progression initiatives and offer opportunities for training and development will be able to attract the most talented young people and retain them for extended periods (Deloitte $\&$ Touche, 2014). Furthermore, leaders face the challenge to manage diverse employees across different ages, generations and gender. Access to life opportunities in South Africa is divided according to gender, language and other dimensions (Keeton, 2014). Women, in particular, lag behind in terms of skills development and work opportunities (Deloitte \& Touche, 2014; Mateus, Allen-Ile \& Iwu, 2014).

\section{The present study}

The aim of the present study is to determine whether the SUDCO questionnaire is universally applicable across three South African language groups by evaluating it statistically for bias and equivalence. The two existing studies that examined cross-cultural validity of the SUDCO in South Africa did so with a limited definition of social group differences (Els, Mostert \& Brouwers, 2016; black vs. white) and with a limited coverage across the South African population (Theron, Mostert \& De Beer, 2015; the WestGermanic language group vs. the African language group, 
but where the African language group consisted mainly of only one out of 11 African languages, namely, Setswana). Furthermore, none of these studies examined the functioning of the SUDCO in relation to primary demographic variables, such as age and gender, variables that uphold valuable individual differences in the face of cross-cultural similarities. Therefore, the present study aimed to determine whether the SUDCO shows meaningful relationships with demographic variables such as age and organisational tenure, and whether gender is a critical moderator.

\section{Research design \\ Research participants}

Data were gathered from employees in the banking sector $(N=658)$ using convenient sampling. Participants with varying demographic characteristics including race, age, gender, education and language were sourced across different organisational levels and departments within one major bank. The demographic characteristics relevant for the present study are displayed in Table 1.

As indicated in Table 1, the sample consisted of 463 females (69.26\%) and 194 males (30.74\%), and one participant did not indicate his/her gender. The youngest employee who participated was 19 years old, with the oldest one 60 years, with a mean age of 31.50 years and a standard deviation of 7.92. Most participants had high school education $(64.10 \%)$, while others had post-matric education (16.60\%). The majority of the sample came from the West-Germanic (English and Afrikaans) language group (44.29\%), followed by the Nguni (isiZulu, isiXhosa, isiNdebele and SiSwati) group (29.22\%) and the Sesotho (South Sesotho, Sepedi and Tswana) group (26.48\%). In terms of organisational tenure, participants were evenly distributed, with the smallest group of $11.10 \%$ employed for less than 1 year, and the largest group of $19.90 \%$ for $2-3$ years. Even though most participants indicated English as their second language, they were proficient in English as it is considered an official requirement for business communication within the bank.

\begin{tabular}{llcc}
\multicolumn{4}{l}{ TABLE 1: Characteristics of participants. } \\
\hline Item & Category & Frequency (658) & Percentage \\
\hline Gender $^{\mathrm{a}}$ & Male & 194 & 30.74 \\
& Female & 463 & 69.26 \\
Language & Nguni & 192 & 29.22 \\
& Sesotho & 174 & 26.48 \\
& West-Germanic & 292 & 44.29 \\
Organisation & < year & 73 & 11.10 \\
tenure & 1 year & 123 & 18.70 \\
& 2-3 years & 131 & 19.90 \\
& 4-7 years & 106 & 16.10 \\
& 8-11 years & 120 & 18.20 \\
& $\geq 12$ years & 105 & 16.00 \\
& Grade 12 & 127 & 19.30 \\
Qualification & Diploma & 422 & 64.10 \\
& University degree & 109 & 16.60 \\
\hline
\end{tabular}

$N=658$.

a, For one participant, the gender is unknown.

\section{Measuring instruments}

A socio-demographic questionnaire was administered to determine the biographical characteristics of participants. Questions were posed to determine age, gender, home language, educational qualifications and ethnicity, as well as external dimensions such as current position, job tenure and level of qualification.

The SUDCO (Van Woerkom et al., 2016) was used to measure strengths use and deficit correction. The SUDCO consists of four sub-scales: (1) POS for strengths use, including eight items (e.g. 'In this organisation, employees can do their jobs in a manner that best suits their strong points', (2) POS for deficit correction, including eight items (e.g. 'This organisation emphasises the development of employees' weak points'), (3) strengths-use behaviour, measured by nine items (e.g. 'I actively look for job tasks I am good at') and (4) deficit-correction behaviour, measured with eight items (e.g. 'In my job, I concentrate on my areas of development'). These four constructs were measured on a 7-point Likert-type scale ranging from 0 (almost never) to 6 (almost always). Van Woerkom et al. (2016) also found the scales to be reliable, reporting Cronbach's alpha values regarding POS for strengths use: $\alpha=0.95$; POS for deficit correction: $\alpha=0.89$; strengths-use behaviour: $\alpha=0.90$; and deficit-correction behaviour: $\alpha=0.90$.

\section{Research procedure}

Permission was obtained from the Group Human Capital (GHC) division of the participating bank to conduct the research within different business units. The GHC division requested that a disclaimer should be stipulated on the questionnaire confirming that the study was not business related but for academic purposes, to which the researcher duly obliged. The research questionnaire was designed as an electronic survey sent to research participants using internal email of the organisation. The questionnaire provided an option to accept or decline participation, thus ensuring the voluntary nature of participation. Participants were also assured of privacy and confidentiality of their responses. Meetings were scheduled with heads of the business unit to present the study objectives and request permission to conduct the survey in their respective areas. The heads then sent the electronic questionnaire to their respective team members to complete the survey at a convenient time. After a week, a reminder was sent to each team, respectively.

\section{Statistical analyses}

The statistical analyses were conducted using a Statistical Package for Social Science (SPSS) Version 22 (SPSS Inc., 2011) and Analyses of Moment Structures (AMOS) Version 22, employing Maximum Likelihood estimation (Arbuckle, 2013). Interpretation of the results adopted both descriptive and inferential statistics (Arbuckle, 2013).

Before analysing the applicability of the SUDCO items across the three language groups in the sample, the SUDCO items 
were checked for outliers, missing values and their dimensionality. Outliers were replaced by a relevant score where possible, or otherwise as a missing score. Cases with $10 \%$ or more of the items missing were removed; otherwise, missing values were replaced by their scale mean (thus leaving no missing values in the eventual dataset). Preliminary analyses were done to establish the number of dimensions underlying the SUDCO. Analyses were conducted in AMOS, comparing the relative fit of four distinct models: the hypothesised fourfactor model; a one-factor model; a model with one personoriented factor and one organisation-oriented factor; and a model with one strengths-use factor and one deficit-correction factor. Overall, fit of the four models was assessed according to the basic statistical and goodness-of-fit indices. Subsequently, fit of the competing models was examined relative to the hypothesised four-factor model. Fit is based on the chi-square $\left(\chi^{2}\right)$ statistic and the goodness-of-fit indices, Root Mean Square Error of Approximation (RMSEA), Comparative Fit Index (CFI) and Standardised Root Mean Square Residual (SRMR), which are evaluated according to their cut-off criteria. The acceptable model fit for indices was evaluated as follows: RMSEA is acceptable below 0.06 and excellent below 0.04; CFI is acceptable above 0.90 and excellent above 0.95 (He \& Van de Vijver, 2012); SRMR values less than 0.08 are generally considered an acceptable fit (Hu \& Bentler, 1999).

The present study utilised recent developments to test item bias and construct equivalence in a single multi-group model in AMOS. A multi-group confirmatory factor analysis (CFA) was conducted to compare the fit of the SUDCO directly across the three language groups. While sample-size requirements do not change from two to three or four factors, having relatively more indicators per factor lowers samplesize requirements (e.g. Wolf, Harrington, Clark \& Miller, 2013). With four factors and eight indicators per factor, a minimum of 150 participants seems acceptable; the subsample sizes of 192, 174 and 292 in the study satisfy the recommended values for CFA. Practically, within CFA bias and equivalence refer to different parameters in the model: measurement weight, measurement intercepts, structural means and measurement residuals. By using models that are nested (i.e. share most parameters, but systematically vary target parameters), their relative fit across cultures could be determined precisely. Again, fit of the models was assessed in terms of the basic statistical and goodness-of-fit indices.

Descriptive data were analysed using the means, standard deviations, reliability and the range (Tredoux \& Durrheim, 2008) to determine scale functioning. In order to assess the reliability of the SUDCO, Cronbach's alpha coefficient of $\geq 0.70$ was considered as acceptable (Nunnally \& Bernstein, 1994).
SPSS was also used to conduct a series of regression analyses, with the four SUDCO scales' means as the dependent variables, and age and organisational tenure as the independent variables. A stepwise procedure that removes the variance associated with age in a first step avoids violation of the possible collinearity between the two independent variables. In order to compare the two genders and three language groups, the analyses were conducted separately in terms of split groups: by gender (two groups), by language (three groups) and by combining gender and language (six groups). Significance of the coefficients and explained proportions of variance were determined by $p$ values smaller than 0.05 or 0.01 .

\section{Results}

The results section follows a strict systematic order. Firstly, the analyses are given of the number of factors in the SUDCO. Secondly, the results are reported of the multi-group analyses of the SUDCO in the three language groups, to assess item bias and construct equivalence. Thirdly, descriptives of the SUDCO scales are reported along their relations with age, organisational tenure, gender and language group.

\section{Factorial validity}

In order to ensure the factorial validity of the internal structures of the SUDCO, four competing models were tested. While model fit is the most important criterion, factor loadings and between-factor correlations are evaluated as well.

Model 1: The hypothesised four-factor model consisting of four sub-scales: POS for strengths use (specified as a first factor with eight items); POS for deficit correction (specified as a second factor with eight items); strengths-use behaviour (specified as a third factor with nine items); deficit-correction behaviour (specified as a fourth factor with eight items).

Model 2: Items of all four sub-scales of POS for strengths use, POS for deficit correction, strengths-use behaviour and deficit-correction behaviour.

Model 3: Organisational factors (POS for strengths use and POS for deficit correction) loaded onto one factor and individual behaviour (strengths-use behaviour and deficitcorrection behaviour) loaded onto one factor.

Model 4: Another two-factor model, comprising strengthsuse variables (POS for strengths use and strengths-use behaviour) and deficit-correction variables (POS for deficit correction and deficit-correction behaviours).

Table 2 shows the fit of the four models that were tested. When reviewing the results for the various models of the

TABLE 2: Results of the competing measurement models.

\begin{tabular}{|c|c|c|c|c|c|c|c|c|c|c|}
\hline Model & $x^{2}$ & $d f$ & $p$ & $\chi^{2} / d f$ & $\Delta \chi^{2}$ & $\Delta d f$ & $\Delta \chi^{2} / \Delta d f$ & CFI & RMSEA & SRMR \\
\hline Model 1 & 1576.05 & 489 & 0.00 & 3.22 & baseline & baseline & baseline & 0.94 & 0.06 & 0.04 \\
\hline Model 2 & 8236.81 & 495 & 0.00 & 16.64 & 6660.76 & 6 & 1110.13 & 0.59 & 0.15 & 0.14 \\
\hline Model 3 & 3719.77 & 494 & 0.00 & 7.53 & 2143.72 & 5 & 783.95 & 0.83 & 1.00 & 0.06 \\
\hline Model 4 & 7353.71 & 494 & 0.00 & 14.89 & 5777.66 & 5 & 1155.53 & 0.64 & 0.14 & 0.15 \\
\hline
\end{tabular}

$\chi^{2}$, chi-square; $d f$, degrees of freedom; $p$, statistical significance; CFI, comparative fit index; RMSEA, root mean square error of approximation; SRMR, standardised root mean square residual. 
SUDCO scales, Model 2 (one-factor model) compared significantly worse to the baseline model (M1) (M2 vs. M1: $\left.\Delta \chi^{2}=6660.76, \Delta d f=6, p \leq 0.00\right)$. In comparing the alternative Model 3 (two factors, organisational and individual behaviour scales) to the baseline Model 1 (four factors, POS for strengths use, POS for deficit correction, strengthsuse behaviour and deficit-correction behaviour), the fit of this alternative model was favourable compared to Model 3 but still not stronger than that of the baseline Model 1 (M3 vs. M1: $\Delta \chi^{2}=2143.72, \Delta d f=5, p \leq 0.00$ ). The finally tested Model 4 (two factors, strengths and deficits scales) was also compared with the baseline Model 1, which proved a worse fit for data compared with Model 3, as well as the baseline model (M4 vs. M1: $\Delta \chi^{2}=7353.71, \Delta d f=5$, $p \leq 0.00$ ). Based on the findings from Table 2 , it is evident that the baseline model (hypothesised model), fitted the data the best, compared with other models $\left(\chi^{2}=1576.05\right.$; $d f=489, \chi^{2} / d f=3.22, p=0.00 ; \mathrm{CFI}=0.94 ; \mathrm{RMSEA}=0.06$; SRMR $=0.04)$. Model 1 showed acceptable model fit as RMSEA < 0.06, CFI values were close to 0.90 (He \& Van de Vijver, 2012) and SRMR values were below 0.08 (Hu \& Bentler, 1999).
Table 3 shows the factor loadings for the latent variables. Factor loading on all items proved to be statistically significant ranging from 0.64 to 0.87 . Regarding POS for strengths use, the smallest loading was for the following item: 'In this organisation, employees can do their jobs in a manner that best suits their strong points', with a loading of 0.72, and the highest loading was for the following item: 'This organisation ensures that people can apply their strong points in their jobs', with a loading of 0.87 . With regard to POS for deficit correcting, the smallest loading was for the following item: 'In this organisation, performance appraisals address people's areas of development', with a loading of 0.71, and the highest loading was for the item: 'In this organisation, development plans are aimed to better people's weaknesses', with a loading of 0.86 . For strengths-use behaviour, the smallest loading was for the item: 'I actively look for job tasks I am good at', with a loading of 0.64 , and the highest loading was for the item: 'I capitalise on my strengths at work', with a loading of 0.84. Finally, for deficitcorrection behaviour, the smallest loading was for the item: 'At work, I seek training opportunities to improve my weaknesses', with a loading of 0.70 , and the highest loading

TABLE 3: Standardised factor loadings of the Strengths Use and Deficit COrrection items on the four latent variables.

\begin{tabular}{|c|c|c|}
\hline Construct & Item & Loading \\
\hline \multicolumn{3}{|l|}{ Perceived Organisational Support for Strengths Use (POSSU) } \\
\hline This organisation uses employees' strengths & POSSU1 & 0.73 \\
\hline In this organisation, employees can do their jobs in a manner that best suits their strong points & POSSU2 & 0.72 \\
\hline In this organisation, employees can do their jobs in a manner that best suits their strong points & POSSU3 & 0.83 \\
\hline In this organisation, people can use their talents & POSSU4 & 0.82 \\
\hline In this organisation, people's job tasks are aligned with their strengths & POSSU5 & 0.86 \\
\hline This organisation makes the most of people's talents & POSSU6 & 0.86 \\
\hline This organisation ensures that people can apply their strong points in their jobs & POSSU7 & 0.87 \\
\hline This organisation focuses on what people are good at & POSSU8 & 0.86 \\
\hline \multicolumn{3}{|l|}{ Perceived Organisational Support for Deficit Correction (POSDI) } \\
\hline This organisation emphasises the development of employees' weak points & POSDI1 & 0.77 \\
\hline In this organisation, employees receive training to improve their weak points & POSDI2 & 0.81 \\
\hline This organisation focuses on people's areas of development & POSDI3 & 0.85 \\
\hline In this organisation, people are required to work on their shortcomings & POSDI4 & 0.75 \\
\hline In this organisation, people are expected to improve the things they are not good at & POSDI6 & 0.72 \\
\hline In this organisation, performance appraisals address people's areas of development & POSDI7 & 0.71 \\
\hline In this organisation, employees receive feedback regarding their limitations & POSDI8 & 0.72 \\
\hline \multicolumn{3}{|l|}{ Strengths-Use Behaviour (SUB) } \\
\hline I actively look for job tasks I am good at & SUB1 & 0.64 \\
\hline I use my strengths at work & SUB2 & 0.80 \\
\hline In my job, I try to apply my talents as much as possible & SUB3 & 0.78 \\
\hline I organise my job to suit my strong points & SUB4 & 0.82 \\
\hline I draw on my talents in the workplace & SUB5 & 0.80 \\
\hline At work, I focus on the things I do well & SUB6 & 0.64 \\
\hline In my job, I make the most of my strong points & SUB7 & 0.78 \\
\hline I capitalise on my strengths at work & SUB8 & 0.84 \\
\hline I seek opportunities to do my work in a manner that best suits my strong points & SUB9 & 0.74 \\
\hline \multicolumn{3}{|l|}{ Deficit-Correction Behaviour (DCB) } \\
\hline I engage in activities to develop my weak points at work & DCB3 & 0.80 \\
\hline In my job, I work on my shortcomings & DCB4 & 0.76 \\
\hline At work, I seek training opportunities to improve my weaknesses & DCB5 & 0.70 \\
\hline I reflect on how I can improve the things in my job I am not good at & DCB6 & 0.79 \\
\hline In my job, I make an effort to improve my limitations & DCB7 & 0.81 \\
\hline At work, I seek feedback regarding my areas of development & DCB8 & 0.73 \\
\hline
\end{tabular}


was for the item: 'In my job, I make an effort to improve my limitations', with a loading of 0.81 . Correlations between the factors show varying patterns: six correlations with values of $0.81,0.48,0.78,0.52,0.51$ and 0.44 for Model 1, no correlations for the single factor Model 2, a correlation of 0.55 for the organisational versus individual Model 3, and a correlation of 0.84 for the strength-use versus deficit-correction Model 4. While Models 1, 3 and 4 all show good discriminant validity, Model 1 is the most detailed and discriminating between the various factors at the same time.

\section{Item bias and structural equivalence}

Item bias and structural equivalence were tested to determine whether the SUDCO can be used across the three language groups. The fit indices of the multi-group CFA across the language groups are reported in Table 4 and the chi-square differences reported in the model comparison function are used to ascertain the level of equivalence across the groups. In CFA, the theoretical model is investigated to see whether it fits the data. Model 0 includes all four parameters where none of the parameters are constrained. In Model 1, only the weights are constrained, while in Model 2, parameters are constrained for weights and intercepts. In Model3, parameters are constrained for weights, intercepts and structural covariances, while in Model 4, parameters for residuals, weights, intercepts and structural covariances are constrained. From the fit indices, it is clear that all four models fit the data well, but a closer look at changes in the chi-square that arise from adding constraints to the null model reveals that Models 3 and 4 create a significantly poorer fit $\left(\Delta \chi^{2}=191.52 ; \Delta d f=144\right.$; $p=0.01$ for Model 3 and $\Delta \chi^{2}=445.02 ; \Delta d f=210 ; p=0.00$ for Model 4). Models 1 and 2 improve equivalence without compromising fit $\left(\Delta \chi^{2}=54.43 ; \Delta d f=58 ; p=0.61\right.$ for Model 1 and $\Delta \chi^{2}=135.35 ; \Delta d f=124 ; p=0.23$ for Model 2), but the analyses show that Model 2 still adds meaningful constraint over Model $1\left(\Delta \chi^{2}=80.92 ; \Delta d f=66 ; p=0.10\right)$. The best-fitting model is Model $2\left(\chi^{2}=3169.13 ; d f=1591 ; \chi^{2} / d f=1.99 ; p=0.00\right.$; $\mathrm{CFI}=0.92$, RMSEA $=0.04$, SRMR $=0.05$ ).

\section{Working with Strengths Use and Deficit COrrection mean scores}

The results indicated that items are consistent with acceptable Cronbach's alpha coefficients regarding POS for strengths use $(\alpha=0.94)$; POS for deficit correction $(\alpha=0.94)$; strengthsuse behaviour ( $\alpha=0.93$ ); and deficit-correction behaviour $(\alpha=0.93)$. These are acceptable as the coefficient closer to 1 is considered a true score (Struwig \& Stead, 2007).

The descriptive statistics reflecting minimums, maximums, means and standard deviations regarding the SUDCO scales for the sample of Nguni, Sesotho and West-Germanic language groups are displayed in Table 5. The outer left column of Table 5 presents the three groups with separate entries for each scale per group. Presented in the table are the minimum and maximum scores, plus in the last two columns the means and standard deviations. When examining the scores, the following findings emerge: while the WestGermanic group shows generally higher scores on all four scales, within each group, the four scales show more or less the same pattern. In other words, the two behaviour scales show consistently higher mean scores than the two POS scales. This pattern indicates homogeneity in scores of the Nguni, Sesotho and West-Germanic groups in relation to the SUDCO scales.

In the present study, comparability and equal functioning of the four SUDCO scales were established for the three mentioned language groups. Thereafter, a series of regression analyses were done to apply the four scales to organisational parameters, in this case, age and organisational tenure. For each regression analysis, one of the SUDCO scale means was chosen as dependent variable, and age and organisational tenure as the independent variables. The dependent variables were entered in a stepwise fashion: first step, age and second step, organisational tenure. High correlation might be expected between the two dependent variables; therefore, this procedure allows the independent estimation of each variable's effect. In order to compare the two genders and

TABLE 5: Descriptive statistics for Strengths Use and Deficit COrrection subscales in the three language groups.

\begin{tabular}{|c|c|c|c|c|c|}
\hline Language groups & Factors & Minimum & Maximum & Mean & SD \\
\hline \multirow[t]{4}{*}{ Nguni } & $\begin{array}{l}\text { POS for strengths } \\
\text { use }\end{array}$ & 1.00 & 7.00 & 3.83 & 1.53 \\
\hline & $\begin{array}{l}\text { POS for deficit } \\
\text { correction }\end{array}$ & 1.00 & 7.00 & 4.34 & 1.47 \\
\hline & $\begin{array}{l}\text { Strengths-use } \\
\text { behaviour }\end{array}$ & 1.00 & 7.00 & 5.37 & 1.23 \\
\hline & $\begin{array}{l}\text { Deficit-correction } \\
\text { behaviour }\end{array}$ & 1.13 & 7.00 & 5.41 & 1.20 \\
\hline \multirow[t]{4}{*}{ West-Germanic } & $\begin{array}{l}\text { POS for strengths } \\
\text { use }\end{array}$ & 1.13 & 7.00 & 4.09 & 1.57 \\
\hline & $\begin{array}{l}\text { POS for deficit } \\
\text { correction }\end{array}$ & 1.00 & 7.00 & 4.63 & 1.54 \\
\hline & $\begin{array}{l}\text { Strengths-use } \\
\text { behaviour }\end{array}$ & 1.89 & 7.00 & 5.61 & 1.17 \\
\hline & $\begin{array}{l}\text { Deficit-correction } \\
\text { behaviour }\end{array}$ & 1.38 & 7.00 & 5.58 & 1.14 \\
\hline \multirow[t]{4}{*}{ Sesotho } & $\begin{array}{l}\text { POS for strengths } \\
\text { use }\end{array}$ & 1.00 & 7.00 & 3.93 & 1.63 \\
\hline & $\begin{array}{l}\text { POS for deficit } \\
\text { correction }\end{array}$ & 1.50 & 7.00 & 4.49 & 1.57 \\
\hline & $\begin{array}{l}\text { Strengths-use } \\
\text { behaviour }\end{array}$ & 2.56 & 7.00 & 5.51 & 1.18 \\
\hline & $\begin{array}{l}\text { Deficit-correction } \\
\text { behaviour }\end{array}$ & 2.13 & 7.00 & 5.60 & 1.25 \\
\hline
\end{tabular}

SD, standard deviation.

TABLE 4: Fit indices of the multi-group confirmatory factor analysis across language groups.

\begin{tabular}{|c|c|c|c|c|c|c|c|}
\hline Model & $x^{2}$ & $d f$ & $p$ & $\chi^{2} / d f$ & CFI & RMSEA & SRMR \\
\hline Model 0 & 3033.77 & 1467 & 0.00 & 2.07 & 0.92 & 0.04 & 0.05 \\
\hline Model 1 & 3088.20 & 1525 & 0.00 & 2.03 & 0.92 & 0.04 & 0.05 \\
\hline Model 2 & 3169.13 & 1591 & 0.00 & 1.99 & 0.92 & 0.04 & 0.05 \\
\hline Model 3 & 3225.30 & 1611 & 0.00 & 2.00 & 0.91 & 0.04 & 0.06 \\
\hline Model 4 & 3478.79 & 1677 & 0.00 & 2.07 & 0.90 & 0.04 & 0.06 \\
\hline
\end{tabular}

$\chi^{2}$, chi-square; $d f$, degrees of freedom; $p$, statistical significance; CFI, comparative fit index; RMSEA, root mean square error of approximation; SRMR, standardised root mean square residual. 
three language groups, the analyses were done separately for a split-group focus: by gender (two groups), language (three groups) and the combination of gender and language (six groups).

The results for all of the regression analyses can be seen in Table 6 . It is visible that the effects per group are split. The first block shows the effects of age: the main effect for the entire sample, the effect of age for males and for females, as well as for Nguni males, West-Germanic males, etc. The second block follows the same outline for organisational tenure, with the findings split into main effects and effects per gender and language group. The findings show that the effects of age are confined mostly to strengths and to females, both regarding POS and behaviour. The largest effects, in this case, are $\beta=0.23, p<0.01$ for POS strengths use and $\beta=0.20$, $p<0.01$ for strengths-use behaviour in Sesotho women, with West-Germanic women showing slightly smaller effects than the Sesotho women. Males only show a significant main effect for POS deficit correction, $\beta=-0.15, p<0.05$.

Regarding organisational tenure, the effect of age is eliminated through stepwise regression procedure (with age as the first step and organisational tenure as the second step). The only significant effects in this case were found for strengths-use behaviour, both males and females showing a main effect $(\beta=-0.15, p<0.05$ and $\beta=-0.15, p<0.05$, respectively). While Sesotho males and females showed high coefficients (0.46 and 0.25$)$ for organisational tenure in relation to strengths-use behaviour, this effect only reached significance for the males $(p<0.05)$. Taken as a whole, the three language groups thus show important and rather consistent functioning in terms of SUDCO scales, with two scales indicating only limited effects, and two other scales moderate effects. The results emphasise the relevance of a positive psychology for personal development, where the effects for strengths are persistently higher than for deficits.

\section{Discussion}

The present study argues for a balanced and comprehensive approach to positive psychology, one which focuses on developing strengths and correcting deficits, at the level of both the organisation and of individual employees. This shift towards a balanced approach in the behaviour of personnel and the organisation (Seligman, 2002; Rust, Diessner \& Reade, 2009) led to the development of the SUDCO (Van Woerkom et al., 2016). Therefore, as indicated previously, the objectives of the present study was to validate the SUDCO in a specific working sample of banking employees. This was done by examining bias and equivalence of the SUDCO across the diverse language groups: Nguni, Sesotho and West-Germanic. Thereafter, the study compared the functioning of the SUDCO within each language group regarding the variables of age, organisational tenure and gender.

The study commenced by validating the factor structure of the SUDCO, in comparing the hypothesised four-factor model with competing models. The analyses indicated that the hypothesised four-factor model provides a significantly better fit based on the fit indices and information criteria. These results are consistent with the research findings of previous studies (Els et al., 2016; Stander \& Mostert, 2013; Van Woerkom et al., 2016).

Cross-cultural psychology investigates whether cultural differences may cause differences in behaviour and whether similarities can be found in psychological behaviour across cultures (De Klerk, 2008). Thus, in cross-cultural studies and psychometric assessments, the taxonomies of bias and equivalence are significant because they provide a theoretical framework to validate these requirements (Van de Vijver \& Leung, 2011; Van de Vijver \& Tanzer, 2004). In order to measure bias and consistency in meaning, the present study

TABLE 6: Strengths Use and Deficit COrrection scale behaviour: Results of the stepwise regression analysis with age, organisational tenure, gender and language group.

\begin{tabular}{|c|c|c|c|c|c|c|c|c|c|c|}
\hline \multirow{2}{*}{$\begin{array}{l}\text { Independent } \\
\text { variable }\end{array}$} & \multirow{2}{*}{$\begin{array}{l}\text { Split group 1: } \\
\text { gender }\end{array}$} & \multirow{2}{*}{$\begin{array}{l}\text { Split group 2: } \\
\text { language }\end{array}$} & \multicolumn{2}{|c|}{ POSSU } & \multicolumn{2}{|c|}{ POSDI } & \multicolumn{2}{|c|}{ SUB } & \multicolumn{2}{|c|}{ DCB } \\
\hline & & & $\beta$ & $\Delta R^{2}$ & $\beta$ & $\Delta R^{2}$ & $\beta$ & $\Delta R^{2}$ & $\beta$ & $\Delta R^{2}$ \\
\hline \multirow[t]{9}{*}{ Age } & - & - & 0.12 & $0.02^{* *}$ & -0.01 & 0.00 & 0.13 & $0.02^{* *}$ & -0.02 & 0.00 \\
\hline & Male & - & -0.04 & 0.00 & -0.15 & $0.02^{*}$ & 0.08 & 0.01 & -0.07 & 0.01 \\
\hline & & Nguni & 0.08 & 0.01 & -0.08 & 0.01 & 0.01 & 0.00 & 0.07 & 0.00 \\
\hline & & West-Germanic & -0.03 & 0.00 & -0.13 & 0.02 & 0.13 & 0.02 & -0.16 & 0.02 \\
\hline & & Sesotho & -0.09 & 0.00 & -0.19 & 0.03 & 0.05 & 0.00 & -0.01 & 0.00 \\
\hline & Female & - & 0.18 & $0.03^{* *}$ & 0.04 & 0.00 & 0.15 & $0.02^{* *}$ & -0.01 & 0.00 \\
\hline & & Nguni & 0.09 & 0.01 & -0.10 & 0.01 & 0.07 & 0.01 & -0.09 & 0.01 \\
\hline & & West-Germanic & 0.20 & $0.04^{* *}$ & 0.05 & 0.00 & 0.15 & $0.02^{*}$ & -0.02 & 0.00 \\
\hline & & Sesotho & 0.23 & $0.05^{*}$ & 0.12 & 0.01 & 0.20 & $0.04^{*}$ & 0.04 & 0.00 \\
\hline \multirow[t]{8}{*}{ OrgTenure } & - & - & 0.06 & 0.00 & 0.05 & 0.00 & 0.15 & $0.01^{*}$ & 0.04 & 0.00 \\
\hline & Male & - & 0.06 & 0.00 & 0.05 & 0.00 & 0.15 & $0.01^{*}$ & 0.04 & 0.00 \\
\hline & & Nguni & -0.33 & 0.06 & -0.34 & 0.06 & -0.10 & 0.01 & -0.12 & 0.01 \\
\hline & & West-Germanic & -0.15 & 0.01 & 0.06 & 0.00 & 0.09 & 0.00 & -0.01 & 0.00 \\
\hline & Female & - & 0.06 & 0.00 & 0.05 & 0.00 & 0.15 & $0.01^{*}$ & 0.04 & 0.00 \\
\hline & & Nguni & 0.15 & 0.01 & 0.01 & 0.00 & 0.19 & 0.02 & 0.24 & 0.03 \\
\hline & & West-Germanic & 0.14 & 0.01 & 0.05 & 0.00 & 0.11 & 0.00 & -0.12 & 0.01 \\
\hline & & Sesotho & -0.19 & 0.01 & -0.05 & 0.00 & 0.25 & 0.02 & 0.07 & 0.00 \\
\hline
\end{tabular}

a, Corrected for effect of age: By means of a stepwise procedure, the effect of age is removed from that of organisational tenure, thus showing true effects of each.

$*, p<0.05 ; * *, p<0.01$ 
investigated whether the theoretical model as a whole was consistent with the data sample from the population of the three language groups. The best-fitting model was Model 2, indicating that the instrument has the same internal meaning across the three mentioned language groups (Nguni, Sesotho, and West-Germanic). These findings are also congruent with those of Els et al. (2016), and Theron et al. (2015), who investigated bias and equivalence of the SUDCO in less comprehensive samples. Even though Model 4 did not show the best fit, this is not a problem as literature indicates that residuals do not have to be the same. In addition, the literature suggests that this is the most vigorous and adaptable approach to test invariance (Steenkamp \& Baumgartner, 1998). These results indicate that the SUDCO items are not biased against any of the Nguni, Sesotho or West-Germanic language groups. It was found that the SUDCO functions similarly for the three language groups.

Analysis of the Cronbach's alpha coefficients indicated that the SUDCO is a consistent measure with values ranging between $\alpha=0.93$ and $\alpha=0.94$ for the different sub-scales. These results show that the SUDCO items will consistently measure the extent to which the bank is perceived to offer its employees organisational support for strengths use and deficit correction. In addition, these scales will measure consistently how the bank employees themselves behave or take the initiative in using their strengths or correcting their deficits. Similarly, Van Woerkom et al. (2016) and Stander and Mostert confirm Cronbach's alpha coefficients ranging between $\alpha=0.89$ and $\alpha=0.95$ for the four sub-scales.

Finally, the SUDCO showed meaningful relationships with demographic variables such as age and organisational tenure in each of the gender, language and gender by language groups. For this aim, a series of regression analyses were conducted. These analyses show that particularly the effects for the two strengths-use dimensions have significant coefficients, in which age and organisational tenure differ between the two. The moderating effect of gender was most visible for age and less for organisational tenure. More specifically, the effects of age related to strengths are stronger for women than for men.

This study contributes to the fair application of psychometric assessments in the South African workplace. As South Africa has 11 official language groups, it is suggested that future research should assess the bias and equivalence of the SUDCO with representatives of all language groups. The present study has dealt with these gaps in the literature, seeing that the researcher established bias and equivalence based on a sample of the three mentioned South African language groups.

\section{Limitations and recommendations}

Although the present study does contribute to the field of psychology, certain limitations were noted, which are discussed subsequently. Firstly, the study focused on employees in the banking sector, where the population consists of employees with a minimum education of Grade 12. However, the South African employment landscape comprises employees from differentiated education levels, and consequently socio-economic levels, who are thus motivated by different factors. It is well documented that employees in the blue-collar sector need to make their ends meet (according to Maslow's hierarchy of needs) and are therefore predominantly motivated by remuneration, rather than personal development (Pink, 2010). On the contrary, employees with tasks involving cognitive skills, decisionmaking and creativity are more motivated to develop themselves in terms of strengths and unique work-related traits (Pink, 2010). It is thus recommended that future research focuses on bias with a sample of a diverse population, which includes people from the different sectors of the economy.

Secondly, while the findings on bias and equivalence are favourable, a limitation was noted on the effects for the dimensions of POS for deficit correction and deficit-correction behaviour. These two scales did not show significant coefficients for age and organisational tenure. While this finding could potentially be an important contribution to the literature, it may also reflect a characteristic of the small sample size: too small to have sufficient power for fruitful testing of significance. However, the two strengths scales do reach significance in the same samples, which suggests that non-significance does reflect the true relationships in the population. Nevertheless, to eliminate concerns about the power of statistical testing, future studies may employ larger sample sizes, just to make sure.

Thirdly, companies have to attend to the influx of people with diverse cultural profiles from the rural areas to the cities, as well as the educational and business systems that encourage the use of English. As a result, certain employees were not clear on what constitutes a home language and asked whether they were allowed to select more than one language. Future cross-cultural studies thus need to define how the population can be categorised into different languages, whether for the business environment, a home dialect or language based on the parental line or ethnicity, in order to make meaningful inferences. Therefore, 'language' needs to be defined in the cross-cultural context, for future studies that plan to investigate equivalence based on language groups.

Fourthly, the present study employed a cross-sectional design, where observations were made of a particular group at a specific period. In order to ensure equitable use of SUDCO, researchers may consider studies on predictive bias. This is based on the premise that any given score on the predictor should result in a similar level of performance for all study participants irrespective of their group membership (Kuncel \& Klieger, 2012). Thus, people from a specific ethnic group (e.g. West-Germanic) who share similar characteristics (e.g. obtained the same rating in the job interview), should perform comparably (not necessarily equally) regardless of group membership. 
Finally, in the cross-sectional design, observations were thus made at specific periods. Because this instrument is relatively new in the industry, to date, no documented longitudinal studies are related to this instrument. Longitudinal studies observe the same group of people or the same measure over an extended period (Goodwin, 2010). This help researchers identify changes in the variables of the sample at both individual and group level.

\section{Practical implications}

The present research's findings have clear practical implications. Employees within the bank are exposed to management feedback, which traditionally focuses on performance management aimed at correcting deficits. These findings can empower employees with the knowledge and value of using a balanced approach, SBA's selfdevelopment initiatives. The value of adopting SBA is that employees become aware of their strengths, which increase their motivation and improve their performance in the work place.

From a practical point of view, demonstrating that strengths use can yield performance benefits, provide leaders and organisations the tools to manage employees' performance and thereby make the organisation more effective (Kong \& Violet, 2016). In line with findings by Sorenson (2014), the present research showed the benefits of investing in employees' selection, strengths and well-being. Such investment may boost the results that companies would receive from increasing its engagement alone. In this regard, the study helps organisations understand their employees' strengths and deficits. This insight will guide companies in attracting, retaining and developing talent. In turn, this increases engagement, well-being, productivity, and maintains the bottom line. For example, employees that proactively attend to their own development of careerrelated skills and abilities have been shown to enhance their well-being (Plomp et al., 2016). The study further contributes to literature in this field, as numerous studies focus on either a strength-based approach or deficit improvement. Strength-based approaches are, for example, a historical reaction to an almost exclusive deficit focus (Wright, 2003), which led to a broad shift in focus to strengths (Van Woerkom \& Meyers, 2014). There is a gap in literature and instruments that provide a balanced approach, which measures both strengths use and deficit correction in the same study.

Furthermore, the significance of the present study is pivotal, by ensuring that the principles of fairness, inclusivity and equity are observed in the organisation (Foxcroft \& Roodt, 2009; Robbins, Judge, Odendaal \& Roodt, 2009). The research contributes to the organisational psychology profession by aiming to validate reliability, bias and structural equivalence of the instrument. The research findings will provide evidence, which may be relevant for the classification of the SUDCO as a legally recognised psychological instrument to be applied in the South African context.

\section{Conclusion}

Literature proved to be limited with regard to knowledge on positive organisations (Gable \& Haidt, 2005). The present research responds to a renaissance of positive psychology as a field that is not limited to the development of strengths, but finding the balance between both strengths and weaknesses (Kaiser \& White, 2008; Seligman et al., 2004). A positive focus on strengths within measures of personnel development makes a substantial contribution to organisations' attempt at keeping their employees on top of their game and committed to their company. The SUDCO shows good evidentiary support for helping managers in the South African workplace to achieve excellence.

\section{Acknowledgements Competing interests}

The authors declare that they have no financial or personal relationships that may have inappropriately influenced them in writing this article.

\section{Authors' contributions}

S.A.B. co-designed the study; supervised the collection of the data; conducted all statistical analyses in the manuscript; wrote the results section; and co-wrote the introduction, literature, method and discussion sections. K.M. co-designed the study and co-wrote the introduction, literature, method and discussion sections. S.V.M. collected the data and cowrote the introduction, literature, method and discussion sections. The article follows from S.V.M.'s dissertation.

\section{References}

Aguinis, H., Gottfredson, R.K., \& Joo, H. (2012). Delivering effective performance feedback: The strengths-based approach. Business Horizons, 55(2), 105-111. Retrieved November 23, 2016, from http://ac.els-cdn.com.nwulib.nwu.ac.za/ 9e11-11e6-aea3-00000aab0f02\&acdnat=1477771065_67f6dc320ee3462e34810 $\mathrm{f} 2 \mathrm{c} 24 \mathrm{dc} 6 \mathrm{c} 2 \mathrm{c}$

Allen, D.G., Shore, L.M., \& Griffeth, R.W. (2003). The role of perceived organizational support and supportive human resource practices in the turnover process. Journal of Management, 29(1), 99-118. https://doi.org/10.1177/014920630302900107

Arbuckle, J.L. (2013). IBM SPSS AMOS 22 user's guide. Crawfordville, FL: Amos Development Corporation. Retrieved November 23, 2016, from http://public.dhe. ibm.com/software/analytics/spss/documentation/amos/22.0/en/Manuals/IBM_ SPSS_Amos_User_Guide.pdf

Armstrong-Stassen, M., \& Ursel, N.D. (2009). Perceived organizational support, career satisfaction, and the retention of older workers. The British Psychological Society, 82(1), 201-220. https://doi.org/10.1348/096317908X288838/full

Belschak, F., \& Hartog, D., (2010). Being proactive at work-blessing or bane? The Psychologist, 23(11), 886-889. Retrieved November 23, 2016, from http://hdl. handle.net/11245/1.328609

Corporate Leadership Council. (2002). Building the high-performance workforce: A quantitative analysis of the effectiveness of performance management strategies. Washington, DC: Corporate Executive Board.

Crant, M.J. (2000). Proactive behaviour in organizations. Journal of Management, 26(3), 435-462. https://doi.org/10.1177/014920630002600304

De Klerk, G. (2008). Cross-cultural testing. In M. Born, C.D. Foxcroft, \& R. Butter (Eds.), Online readings in testing and assessment. International test commission. Retrieved November 23, 2016, from http://www.intestcom.org/Publications/ ORTA.php

Deloitte \& Touche. (2014). South Africa human capital trends: Engaging 21st century workforce. Johannesburg: Deloitte \& Touche. Retrieved November 23, 2016, from http://www2.deloitte.com/content/dam/Deloitte/global/Documents/ HumanCapital/dttl-2014-Human\%20Capital\%20Trends\%20South\%20Africa.pdf

Department of Labour. (1998). Employment Equity Act 55 of 1998. Pretoria, South Africa: Government Printers. Retrieved November 23, 2016, from http://www. saflii.org/za/legis/consol_reg/eea55o1998rangnr1085683/ 
Director, S., Cascio, W.F., \& Boudreau, J. (2013). Key tools for human resource management. Upper Saddle River, NJ: Pearson Education.

Echols, M.E. (2005). Engaging employees to impact performance. Bellevue, NE: Bellevue University.

Eisenberger, R., Fasolo, P., \& Davis-LaMastro, V. (1990). Perceived organizational support and employee diligence, commitment and innovation. Journal of Applied Psychology, 75(1), 51-59. https://doi.org/10.1037/0021-9010.75.1.51

Eisenberger, R., Huntington, R., Hutchison, S., \& Sowa, D., (1986). Perceived organizational support. Journal of Applied Psychology, 71(3) 500-507. https://doi. org/10.1037/0021-9010.71.3.500

Ellinger, A.D. (2003). Antecedents and consequences of coaching behaviour. Performance Improvement Quarterly, 16(1), 5-28. Retrieved November 23, 2016 from, http:// onlinelibrary.wiley.com.nwulib.nwu.ac.za/doi/10.1111/j.1937-8327.2003. tb00269.x/epdf

Els, C., Mostert, K., \& Brouwers, S. (2016). Bias and equivalence of the Strengths Use and Deficit COrrection Questionnaire. SA Journal of Industrial Psychology, 42(1), 1-9. https://doi.org/10.4102/sajip.v42i1.1365

Ericsson, K.A., Nandagopal, K., \& Roring, R.W. (2009). Toward a science of exceptional achievement. Longevity, Regeneration, Optimal Health, 1172, 199-217. https:// achievement. Longevity, Regeneratio
doi.org/10.1196/annals.1393.001

Foxcroft, C., \& Roodt, G. (2009). Introduction to psychological assessment in the South African context (3rd ed.). Cape Town: Oxford University Press.

Gable, S.L., \& Haidt, J. (2005). What (and why) is positive psychology? Review of general psychology, 9(2), 103-110. Retrieved November 23, 2016, from http:// psycnet.apa.org.nwulib.nwu.ac.za/doi/10.1037/1089-2680.9.2.103

Gilley, A., Gilley, J.W., \& Kouider, E. (2010). Characteristics of management coaching. Performance Improvement Quarterly, 53-70. https://doi.org.nwulib.nwu.ac. za/10.1108/00197851011013698

Goodwin, C.J. (2010). Research in psychology: Methods and design. Hoboken, NJ: John Wiley \& Sons

Govindji, R., \& Linley, P.A. (2007). Strengths use, self-concordance and well-being: Implications for strengths coaching and coaching psychologists. International Implications for strengths coaching and coac
Coaching Psychology Review, 2(2), 143-153.

He, J., \& Van de Vijver, F. (2012). Bias and equivalence in cross-cultural research. Online Readings in Psychology and Culture, 2(2), 1-19. https://doi. org/10.9707/2307-0919.1111

Hu, L., \& Bentler, P.M. (1999). Cut-off criteria for fit indexes in covariance structure analysis: Conventional criteria versus new alternatives. Structural Equation 10705519909540118

Kaiser, R.B., \& White, R.P. (2008). Strength test: Debunking an unbalanced approach to development. Leadership in Action, 28(5), 8-12. https://doi.org/10.1002/ lia.1261/full

Keenan, E., \& Mostert, K. (2012). The factorial validity and reliability of a newlydeveloped strength-based approach scale in a sample of South African employees (Master's dissertation). Retrieved November 23, 2016, from http://dspace.nwu. ac.za.nwulib.nwu.ac.za/bitstream/handle/10394/8083/Keenan_E. pdf? sequence $=2 \&$ isAllowed $=\gamma$

Keeton, G. (2014). Inequality in South Africa. The Journal of the Helen Suzman Foundation 74, 26-31. Retrieved November 23, 2016, from file:///C:/Users/ A216840/Documents/Nga/SUDIQ/SUDIQ\%202016/Strengths\%20Use $\% 20$ and $\% 20$ Deficit $\% 20$ Improvements $/ 5 . \% 20$ Inequality $\% 20$ in $\% 20$ South $\% 20$ Africa $\% 20-\% 20 \mathrm{G} \% 20$ Keeton.pdf

Kirkpatrick, D. (2006). Improving employee performance through appraisal and coaching. New York: American Management Association.

Kong, D.T., \& Ho, V.T. (2016). A self-determination perspective of strengths use at work: Examining its determinant and performance implications. The Journal of Positive Psychology, 11(1), 15-25. https://doi.org/10.1080/17439760.2015.1004555

Kuncel, N.R., \& Klieger, D.M. (2012). Predictive bias in work and educational settings. In N. Schmitt, (Eds.), The oxford handbook of personnel assessment and selection In N. Schmitt, (Eds.), The oxford handbook of personn
(pp. 462-484). New York: Oxford University Press.

Linley, P.A., \& Harrington, S. (2006). Strengths coaching: A potential-guided approach to coaching psychology. International Coaching Psychology Review, 1(1), 37-46.

Linley, P.A., Nielsen, K.M., Gillett, R., \& Biswas-Diener, R. (2010). Using signature strengths in pursuit of goals: Effects on goal progress, need satisfaction, and wellbeing, and implications for coaching psychologists. International Coaching Psychology Review, 5(1), 6-15

Longenecker, C.O. (2010). Coaching for better results: Key practices of high performance leaders. Industrial and Commercial Training, 43(1), 32-40. https:// doi.org.nwulib.nwu.ac.za/10.1108/00197851011013698

Mateus, A.D., Allen-lle, C., \& Iwu, C.G. (2014). Skills shortage in South Africa: Interrogating the repertoire of discussions. Mediterranean Journal of Social Sciences, 5(6), 63-73. https://doi.org/10.5901/mjss.2014.v5n6p63

Meiring, D., Van de Vijver, A.J., \& Rothmann, S. (2007). Bias and equivalence of psychological measures in South Africa. Ridderkerk, The Netherlands: Ridderprint.

Meyers, M.C., \& Van Woerkom, M. (2016). Effects of a strengths intervention on general and work-related well-being: The mediating role of positive affect. Journal
of Happiness Studies, 18, 671-689. https://doi.org/10.1007/s10902-016-9745-x

Nunnally, J.C., \& Bernstein, I.H. (1994). Psychometric theory. (3rd edn.). New York: McGraw-Hill.

Pink, D. (2010). Drive: The surprising truth about what motivates us. New York, NY: Canongate.
Plomp, J., Tims, M., Akkermans, J., Khapova, S.N., Jansen, P.G.W., \& Bakker, A.B. (2016). Career competencies and job crafting: How proactive employees influence their well-being. Career Development International, 21, 587-602. https://doi. their well-being. Career Develop

Podsakoff, P.M., MacKenzie, S.B., \& Podsakoff, S.P. (2012). Sources of method bias in social science research and recommendations on how to control it. Annual Reviews of Psychology, 63, 539-569. https://doi.org/10.1146/annurev-psychReviews of Psycho

Robbins, S.P., Judge, T.A., Odendaal, A., \& Roodt, G. (2009). Organisational behaviour: Global and South African perspectives. Cape Town: Prentice Hall.

Rowold, J., \& Schilling, J. (2006). Career-related continuous learning: Longitudinal predictive power of employees' job and career attitudes. Career Development International, 11(6), 489-503. Retrieved November 23, 2016, from http://www. emeraldinsight.com.nwulib.nwu.ac.za/doi/full/10.1108/13620430610692917

Rust, T., Diessner, R., \& Reade, L. (2009). Strengths only or strengths and relative weaknesses? A preliminary study. Journal of Psychology, 143, 465-476.

Seligman, M.E.P. (2002). Authentic happiness. New York: Free Press.

Seligman, M.E.P., \& Csikszentmihalyi, M. (2014). Positive psychology: An introduction. In M. Csikszentmihalyi, (Ed.), Flow and the foundations of positive psychology (pp. 279-298). Claremont, CA: Springer Science \&Business Media.

Seligman, M.E.P., Park, A.C., \& Steen, T. (2004). A balanced psychology and a full life. Philosophical Transactions of the Royal Society of London, B, 359, 1379-1381.

Sorenson, S. (2014). How employees' strengths make your company stronger. Gallup Business Journal. Retrieved November 23, 2016, from http://www.gallup.com/ businessjournal/167462/employees-strengths-company-stronger.aspx

Stander, F.W., \& Mostert, M. (2013). Assessing the organisational and individual strengths use and deficit improvement amongst sport coaches. SA Journal of Industrial Psychology, 39(2), 1-13. https://doi.org/10.4102/sajip.v39i2.1160

Steenkamp, J.B., \& Baumgartner, H. (1998). Assessing measurement invariance in cross-national consumer research. Journal of Consumer Research, 25, 78-90. Retrieved November 23, 2016, from http://www.jstor.org.nwulib.nwu.ac.za/ stable/pdf/10.1086/209528.pdf

Struwig, F.W., \& Stead, G.B. (2007). Planning, designing and reporting research. South Africa, Cape Town: Pearson Education.

Theron, B., Mostert, K., \& De Beer, L. (2015). Proactive behaviour towards strengths use and deficit improvement: Validating a scale for first-year university students.
Unpublished master's dissertation. Potchefstroom: North-West University.

Thompson, J.A. (2005). Proactive personality and job performance: A social capital perspective. Journal of Applied Psychology, 90(5), 1011-1017. https://doi. perspective. Journal of Applied
org/10.1037/0021-9010.90.5.1011

Tombaugh, J.R. (2005). Positive leadership yields performance and profitability: Effective organizations develop their strengths. Development and Learning Organisations, 19(3), 15-17. https://doi.org/10.1108/14777280510590031

Torrente, P., Salanova, M., Llorens, S., \& Schaufeli, W.B. (2012). Teams make it work: How team work engagement mediates between social resources and performance in teams. Psicothema, 24(1), 106-112. Retrieved November 23, 2016, from http:// www.unioviedo.es/reunido/index.php/PST/article/view/9111

Tredoux, C., \& Durrheim, K. (2008). Numbers, hypotheses and conclusions: A course in statistics for social science. Cape Town: University of Cape Town Press.

Van de Vijver, F.J., \& Leung, K. (1997). Methods and data analyses of comparative research. In J.W. Berry, Y.H. Poortinga, \& J. Pandey, (Eds.), Handbook of crosscultural psychology (pp. 257-300). Boston, MA: Allyn \& Bacon.

Van de Vijver, F.J., \& Leung, K., (2011). Equivalence and bias: A review of concepts, models, and data analytic procedures. In D. Matsumoto, F. Van de Vijver, (Eds.), Cross cultural research methods in psychology, (pp. 17-45). New York: Cambridge University Press.

Van de Vijver, F.J., \& Tanzer, N.K. (1997). Bias and equivalence in cross-cultural assessment: An overview. European Review of Applied Psychology, 47(4), 263-279.

Van Woerkom, M. \& Meyers, M.C. (2014). My strengths count! Effects of a strengthsbased psychological climate on positive affect and job performance. Human Resource Management, 54(1), 1-23. https://doi.org/10.1002/hrm.21623

Van Woerkom, M., Mostert, K., Els, C., Bakker, A.B., De Beer, L., \& Rothmann Jr., S. (2016). Strengths use and deficit correction in organizations: Development and validation of a questionnaire. European Journal of Work and Organizational validation of a questionnaire. European Journal of Work and Organiza
Psychology, 25, 1-16. https://doi.org/10.1080/1359432X.2016.1193010

Van Woerkom, M., Oerlemans, W., \& Bakker, A.B. (2016). Strengths use and work engagement: A weekly diary study. European Journal of Work and Organizational Psychology, 25(3), 384-397. https://doi.org/10.1080/1359432X.2015.1089862

Wolf, E.J., Harrington, K.M., Clark, S.L., \& Miller, M.W. (2013). Sample size requirements for structural equation models: An evaluation of power, bias, and solution propriety. Educational and Psychological Measurement, 73, 913-934. https://doi. org/10.1177/0013164413495237

Wright, T.A. (2003). Positive organizational behavior: An idea whose time has truly come. Journal of Organizational Behavior, 24, 437-442. https://doi.org/10.1002/ job.197

Xanthopoulou, D., Bakker, A.B., Demerouti, E., \& Schaufeli, W.B. (2009). Reciprocal relationships between job resources, personal resources, and work engagement. Journal of Vocational behaviour, 74(3), 235-244. https://doi.org/10.1016/j. jvb.2008.11.003

Zenger, J. (2008). Developing strengths or weaknesses: Overcoming the lure of wrong choice. Orem, UT: Folkman. 